BMJ Open Sport \& Exercise Medicine

\title{
What are the perceptions of runners and healthcare professionals on footwear and running injury risk?
}

\author{
Gurmeet K Dhillon, ${ }^{1}$ Michael A Hunt (1D , ${ }^{2,3}$ Andrea L Reid, ${ }^{1,2}$ \\ Jean-Francois Esculier (1D) 1,2,3,4
}

To cite: Dhillon GK, Hunt MA, Reid AL, et al. What are the perceptions of runners and healthcare professionals on footwear and running injury risk? BMJ Open Sport \& Exercise Medicine 2020;6:e000767. doi:10.1136/ bmjsem-2020-000767

- Additional material is published online only. To view please visit the journal online (http://dx.doi.org/10.1136/ bmjsem-2020-000767)

Accepted 27 May 2020

\section{Check for updates}

(c) Author(s) (or their employer(s)) 2020. Re-use permitted under CC BY-NC. No commercial re-use. See rights and permissions. Published by BMJ.

${ }^{1}$ Allan McGavin Sports Medicine Clinic, Vancouver, British Columbia, Canada

${ }^{2}$ Department of Physical

Therapy, The University of British Columbia, Vancouver, British

Columbia, Canada

${ }^{3}$ Motion Analysis and Biofeedback Laboratory, University of British Columbia, Vancouver, British Columbia, Canada

${ }^{4}$ The Running Clinic, LacBeauport, Quebec, Canada

Correspondence to Dr Jean-Francois Esculier; jean-francois.esculier@ubc.ca

\section{ABSTRACT}

Objectives There is a gap in research exploring perceptions of runners and healthcare professionals (HCPs) about running footwear and injury risk. The objectives of this study were: (1) to document factors considered by runners when selecting footwear; (2) to compare perceptions on footwear and injury risk in runners and HCPs; and (3) to evaluate the perceived usefulness of an online educational module.

Methods Using an online survey, we collected information on demographics and perceptions about footwear and injury risk. Runners reported their footwear selection strategy, and HCPs their typical recommendations. An evidence-based educational module was presented, and participants rated its usefulness.

Results The survey was completed by 2442 participants, of which 1035 completed the optional postmodule questions. Runners reported relying mostly on comfort and advice from retailers when selecting shoes. Perceptions regarding the effects of specific footwear types (minimalist, maximalist), characteristics (softness, drop) and selection strategy (foot type, transition) on biomechanics and injury risk were different between HCPs and runners. Overall, runners perceived footwear as more important to prevent injury than did $\mathrm{HCPs}(7.6 / 10,99 \% \mathrm{Cl} 7.4$ to 7.7 vs $6.2 / 10$, $99 \% \mathrm{Cl} 6.0$ to $6.5 ; \mathrm{p}<0.001)$. Both runners $(8.1 / 10,99 \% \mathrm{Cl}$ 7.9 to 8.3$)$ and $\mathrm{HCPs}(8.7 / 10,99 \% \mathrm{Cl} 8.6$ to 8.9$)$ found the educational module useful. A majority of respondents indicated the module changed their perceptions.

Conclusion Footwear is perceived as important in reducing running injury risk. This online module was deemed useful in educating about footwear evidence. Future studies should evaluate if changes in perceptions can translate to behaviour change and, ultimately, reduced injury risk.

\section{INTRODUCTION}

Running injuries can significantly impact the ability of runners to maintain a healthy lifestyle that includes regular physical activity, ${ }^{1}$ which can potentially have a negative impact on physical and psychological health. Footwear manufacturers have designed many technologies in an effort to address biomechanical factors associated with injuries, such as the vertical loading rate (VLR) of the ground
What are the new findings?

- Overall, both runners and healthcare providers (HCPs) perceive running footwear to be important in reducing running injury risk.

- Perceptions regarding the effects of specific footwear types, characteristics and selection strategy on biomechanics and injury risk were different between $\mathrm{HCPs}$ and runners.

- Runners and HCPs found the online educational module designed in this study useful.

- It remains unknown if such a module could lead to behaviour change and, ultimately, reduced injury risk.

reaction force, and lower limb joint forces. ${ }^{2-6}$ However, scientific evidence showing any consistent benefits of these technological features on injury risk is lacking. ${ }^{78}$ According to randomised controlled trials, cushioning features such as heel to toe drop and midsole hardness, ${ }^{9} 10$ as well as recommending footwear based on foot type, ${ }^{11-13}$ have failed to reduce injuries.

While research has yet to show the superiority of maximalist or minimalist shoes in preventing injuries, it is apparent that various types of footwear cause runners to run differently and shift loads to different body parts. ${ }^{14}$ Greater running shoe cushioning tends to increase VLR ${ }^{15-17}$ and knee joint forces, ${ }^{18}$ but decrease ankle forces and peak foot pressure. Conversely, lower cushioning tends to shift initial foot contact closer to the midfoot or forefoot, thus decreasing $\mathrm{VLR}^{19}$ and knee joint forces, ${ }^{20-22}$ but increasing ankle forces and foot pressure. ${ }^{22}$

Runners and healthcare professionals (HCPs) may or may not be aware of the current state of research on running shoes. There is a clear gap in research exploring the perceptions about running footwear and injuries among runners and HCPs, which has the potential to influence behaviour and running shoe selection. ${ }^{23}$ Educating these groups on 
current evidence pertaining to footwear is important, and may potentially aid in reducing injury risk. The primary objectives of this study were: (1) to document factors considered by runners when selecting running footwear; and (2) to report and compare the perceptions of runners and HCPs on the influence of running footwear on running biomechanics and injury risk. Second, we aimed to (3) evaluate the uptake and perceived usefulness of an online evidence-based educational module in both runners and HCPs, and to conduct exploratory analyses on its effects on perceptions.

\section{METHODS}

\section{Participants}

A web-based survey was conducted between 10 April and 30 June 2019. Participants were recruited through social media (Twitter, Facebook, Instagram, LinkedIn), running groups and sports equipment stores. To be included, all participants had to be aged 18 years and older, have access to the internet to fill out the survey and speak English or French. Runners also had to declare that they ran either recreationally or competitively at least once per week for a minimum of 1 month, while HCPs had to declare a license to practice a medical profession (eg, medical doctor, physiotherapist, chiropractor, athletic therapist, podiatrist, pedorthist, osteopath).

\section{Study design}

After providing electronic informed consent and selfidentifying as either runner or HCP, participants were directed to the corresponding set of questions on demographics and perceptions about the importance of shoes in reducing injury risk. Thereafter, participants were offered the opportunity to read an optional educational module summarising the current state of evidence about running footwear and injuries. After reading the module, participants were asked to rate its usefulness and responded to the same set of questions, to enable exploratory analyses on the effects of the module on perceptions. The design and administration of the survey consisted of five steps. The final version of the survey and educational module was designed with the help of runners, running shoe retailers and HCPs from the community. Patients and/or the public were involved in the design, or conduct, or reporting or dissemination plans of this research.

Step 1. Designing the first version of the online survey and educational module

We reviewed the scientific literature on running footwear and running injuries and synthesised findings into main constructs. First, we retrieved articles on the association between running biomechanics and running injuries, which outlined VLR ${ }^{236}$ and joint loads ${ }^{45}$ as relevant risk factors. Second, we identified the definition of minimalist shoes ${ }^{24}$ and the literature pertaining to the effects of minimalist ${ }^{19-22}$ and maximalist ${ }^{15-18}$ footwear on VLR and joint loading. Third, we identified clinical trials on the effects of cushioning density ${ }^{9}$ and heel to toe drop $^{10}$ on running injuries. Fourth, we retrieved information on how transitioning between different footwear categories can increase injury risk. ${ }^{25}$ Fifth, we identified studies related to the prescription of footwear according to foot type and injury risk. ${ }^{11-13}$ When available, we prioritised systematic reviews and randomised clinical trials as references for the educational module. A total of 12 educational infographics were built and grouped into five sections.

The general set of PRE questions pertained to demographics and perceptions about the importance of shoes in reducing running injury risk, as well as their effects on lower limb biomechanics. We ensured that questions were related to the information presented in the module. Runners also provided information about their running habits, criteria for selecting running shoes and sources of information on footwear. The HCPs subgroup answered questions about the importance of footwear in the treatment of running injuries, and clinical recommendations pertaining to runners with knee or foot pain. The first version of PRE included seven questions that were common to both subgroups. Ten and five additional questions were designed for runners and HCPs, respectively. Some questions included subquestions.

Finally, we designed questions for POST, including the overall perceived usefulness of the module. Some questions were duplicates from PRE, enabling us to explore if the module changed the participants' perceptions. Finally, a series of questions were included to ascertain whether the module changed how participants would select their next pair of shoes (runners) or provide clinical recommendations in the future (HCPs). A total of six and seven questions were designed for runners and HCPs, respectively, of which four were identical between groups.

\section{Step 2. Feedback on the online survey and education module}

The first version of the survey and educational module was sent out for review to individuals external to the research team. Six individuals (two runners, two footwear retailers, two HCPs) provided feedback on the relevance, clarity and interpretation of questions, as well as on the clarity, design and relevance of the educational module.

\section{Step 3. Finalising survey items and educational module}

Following feedback, we modified wording for 8 survey questions as well as wording and design of all 12 infographics. We also added multiple choice options for survey questions. The full version of the survey and educational module can be found in online supplementary files 1-2.

\section{Step 4. Translating the survey and educational module}

One member of the research team (JFE) translated the final version of the survey questions and module into French. The French version was sent out for review to three runners, one footwear retailer and one HCP who 
had French as their first language. Minor modifications to wording were made before reaching the final version.

\section{Step 5. Administrating the survey and education module}

Online versions of the English and French questionnaires and module were housed on the XM Qualtrics survey system (www.qualtrics.com). After selecting their language and reading an overview of the study objectives and inclusion criteria, participants provided consent and self-identified as a runner or HCP. Following completion of the survey, the optional educational module was provided to those who expressed interest. Finally, participants were offered the opportunity to respond to the POST questions. Perceptions about the importance of footwear in preventing and treating injuries, as well as the usefulness of the module were rated on scales ranging from 0 to $10(0=$ 'Not important/useful', $10=$ 'Very important/useful'). Agreement with statements about potential effects of footwear on biomechanics and injuries and clinical recommendations was assessed using scales ranging from -10 to $10(-10=$ 'Strongly disagree', $0=$ 'Neutral/Uncertain', $10=$ 'Strongly agree') .

\section{Data analysis}

English and French survey data were merged into a Microsoft Excel (V.2016) spreadsheet and analysed by subgroups of runners (RUN) and HCPs. Perceptions of RUN and HCPs at PRE (continuous variables) were compared using independent t-tests (normal distributions) or Mann-Whitney U tests (non-normal distributions). Perceptions between participants who responded to PRE only were compared with those of participants who responded to PRE and POST using similar methods. Finally, exploratory analyses were conducted to evaluate the effects of the module on perceptions. Specifically, PRE and POST scores for both RUN and HCPs were compared using paired t-tests (normal distributions) or Wilcoxon signed-rank tests (non-normal distributions). For HCPs, recommendations to runners with knee or foot pain (categorical variables) were dichotomised and proportions were compared between PRE and POST using McNemar's test $(2 \times 2$ tables $)$. The $\alpha$ level was set at 0.01 , and all point estimates were supplemented with 99\% CIs. Statistical analyses were conducted using the Statistical Package for Social Sciences (SPSS, Armonk, New York, USA), V.22.

\section{RESULTS}

\section{Participants}

A total of 2442 participants completed the PRE survey out of 4520 individuals who visited the study website (RUN: $\mathrm{n}=1564$; HCPs: $\mathrm{n}=878 ; 54.0 \%$ of all visitors $)$. The optional POST questions were completed by 1035 participants (RUN: $n=621$; HCPs: $n=414$; retention $=42.4 \%$ of PRE respondents). Of note, $87.1 \%$ of HCPs self-identified as regular runners. Demographic information for both subgroups is provided in table 1. Running-specific characteristics for runners are presented in table 2 .

\section{Selection of footwear and sources of advice}

RUN most commonly valued comfort, performance and injury prevention when selecting footwear (figure 1A). Comfort $(n=699)$ was the most frequent primary criterion, followed by injury prevention $(\mathrm{n}=197)$ and performance $(\mathrm{n}=177)$. Footwear retailers $(\mathrm{n}=409)$, specialised websites $(n=287)$ and HCPs $(n=209)$ were the most common primary sources of advice on running shoes (figure 1B).

\section{Perceptions about footwear and injuries}

RUN considered footwear more important in reducing injury risk than did HCPs $(7.6,99 \%$ CI 7.4 to 7.7 vs 6.2 , $99 \%$ CI 6.0 to $6.5 ; \mathrm{p}<0.001$, table 3 ). RUN were relatively neutral with regards to minimal $(0.2,99 \%$ CI -0.2 to 0.6$)$ or maximal $(-0.2,99 \% \mathrm{CI}-0.6$ to 0.3$)$ cushioning helping to decrease ground impact and knee joint forces. In contrast, HCPs moderately disagreed with the statement that maximal cushioning helped decrease impact and knee joint load ( $-4.6,99 \% \mathrm{CI}-5.2$ to 4.1$)$, and tended to agree that minimal cushioning helped decrease impact and knee joint load (2.5, 99\% CI 1.9 to 3.0). Both subgroups

Table 1 Demographics of participants

\begin{tabular}{|c|c|c|c|}
\hline & RUN ( $n=1564)$ & HCPs $(n=878)$ & All $(n=2442)$ \\
\hline Age (years, Mean \pm SD) & $38.1 \pm 10.5$ & $33.9 \pm 8.5$ & $36.6 \pm 10.0$ \\
\hline \multicolumn{4}{|l|}{ Gender, n (\%) } \\
\hline Woman & $520(33.2)$ & $306(34.9)$ & $826(33.8)$ \\
\hline Man & $1034(66.1)$ & $570(64.9)$ & $1604(65.7)$ \\
\hline Transgender, non-binary & $4(0.3)$ & $1(0.1)$ & $5(0.2)$ \\
\hline Prefer not to answer & $6(0.4)$ & $1(0.1)$ & $7(0.3)$ \\
\hline \multicolumn{4}{|l|}{ Level of education, $n$ (\%) } \\
\hline Less than high-school diploma & $32(2.0)$ & $0(0)$ & $32(1.3)$ \\
\hline High-school diploma & $254(16.2)$ & $0(0)$ & $254(11.2)$ \\
\hline Non-university degree/certificate/diploma & $187(12.0)$ & $60(6.8)$ & $247(9.3)$ \\
\hline University degree & $1091(69.8)$ & 818 (93.2) & 1909 (78.2) \\
\hline
\end{tabular}

HCPs, healthcare professionals; RUN, runners. 


\begin{tabular}{lc}
$\begin{array}{l}\text { Table } 2 \text { Self-Reported characteristics of the RUN } \\
\text { subgroup ( } \mathrm{n}=1564)\end{array}$ \\
\hline Running experience (years) & $8.8 \pm 8.2$ \\
\hline Average weekly running distance (km) & $38.6 \pm 24.2$ \\
\hline Longest distance in 1 day/session, $\mathrm{n}(\%)$ & \\
\hline$<5 \mathrm{~km}$ & $13(0.8)$ \\
\hline $5 \mathrm{~km}$ & $36(2.3)$ \\
\hline $10 \mathrm{~km}$ & $179(11.4)$ \\
\hline Half-marathon (21.1 km) & $470(30.1)$ \\
\hline Marathon (42.2 km) & $419(26.8)$ \\
\hline Ultra-marathon (50 km and more) & $447(28.6)$ \\
\hline Running frequency (times/week), $\mathrm{n}(\%)$ & \\
\hline 1-2 & $292(18.7)$ \\
\hline 3-4 & $925(59.1)$ \\
\hline $5-6$ & $294(18.8)$ \\
\hline $7+$ & $53(3.4)$ \\
\hline Member of a running club/group, $\mathrm{n}(\%)$ & $656(41.9)$ \\
\hline Current shoes, $\mathrm{n}(\%)^{*}$ & \\
\hline Traditional (road), motion control & $156(10.0)$ \\
\hline Traditional (road), stability & $304(19.4)$ \\
\hline Traditional (road), neutral & $613(39.2)$ \\
\hline Traditional (trail) & $597(38.2)$ \\
\hline Maximalist (road) & $104(6.6)$ \\
\hline Maximalist (trail) & $141(9.0)$ \\
\hline Minimalist (road) & $408(26.1)$ \\
\hline Minimalist (trail) & $346(22.1)$ \\
\hline Racing flat & $132(8.4)$ \\
\hline Unsure & $83(5.3)$ \\
\hline
\end{tabular}

${ }^{*}$ Total adds up to over $100 \%$ since respondents could report using more than one type of footwear.

generally disagreed that softer shoe soles and greater heel to toe drop decreased injury risk, although HCPs showed a greater level of disagreement $(\mathrm{p}<0.001$, table 3$)$. Both
RUN (5.1, 99\% CI 4.8 to 5.4$)$ and HCPs (5.9, 99\% CI 5.5 to 6.3) agreed that transitioning to different footwear could increase injury risk. Finally, RUN tended to agree that selecting shoes according to foot type would decrease injury risk (1.6, 99\% CI 1.2 to 2.1), while HCPs moderately disagreed $(-4.1,99 \% \mathrm{CI}-4.7$ to $3.6, \mathrm{p}<0.001$, table 3$)$.

Overall, HCPs perceived footwear as moderately important for treating running injuries $(5.9,99 \%$ CI 5.7 to 6.1 ). They generally agreed that injured and uninjured runners required different footwear recommendations (3.5, 99\% CI 3.0 to 4.0). The majority of HCPs reported usually recommending less cushioning to runners with knee pain $(61.6 \%)$ and more cushioning to runners with foot pain $(53.9 \%)$.

Perceptions between individuals who responded only to PRE and those who responded to both PRE and POST were significantly different for all questions, except for the risk of injury related to transitioning to a different category of footwear (table 4). However, their age $(p=0.879)$, gender $(p=0.783)$, level of education $(\mathrm{p}=0.012)$ or running experience $(\mathrm{p}=0.06)$ was not found to be significantly different at the $\alpha=0.01$ level.

\section{Educational module: uptake, usefulness and changes in perceptions}

The module was deemed useful to learn about current evidence on running shoes, with HCPs rating it slightly higher than RUN $(8.7,99 \%$ CI 8.6 to 8.9 vs $8.1,99 \%$ CI 7.9 to $8.3 ; \mathrm{p}<0.001)$. A majority $(62.3 \%)$ of RUN declared having changed their perceptions after reading the module, while $50.1 \%$ mentioned that it would change how they select their next pair of shoes. In the HCPs subgroup, $54.8 \%$ said the module changed their perceptions, and $58.7 \%$ mentioned that it would change their future footwear recommendations. In regards to treating runners with knee pain, significantly more HCPs reported that they would recommend less cushioning after reading the module $(+19.2 \%, \mathrm{p}<0.001)$. Conversely, a greater number of HCPs said that they would recommend more cushioning to runners with foot pain after reading the module $(+12.3 \%, \mathrm{p}<0.001$, online supplementary file 3$)$.
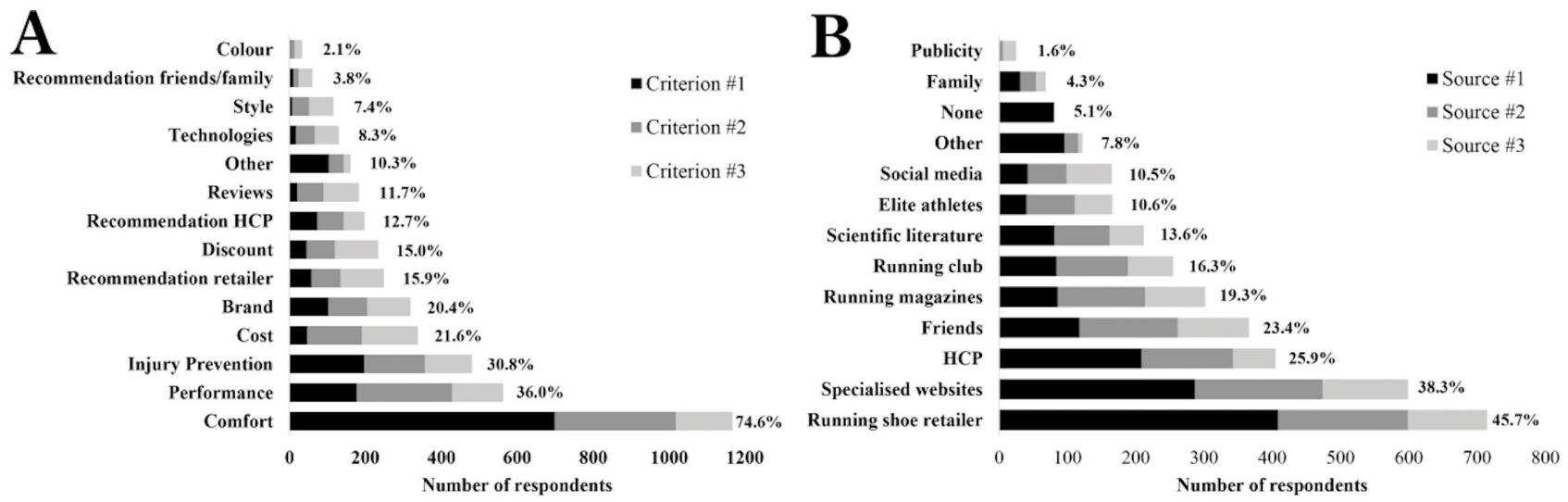

Figure 1 (A) Main criteria for RUN when selecting running shoes and (B) main sources of footwear recommendations $(n=1564)$. RUN, runners. 
Table 3 Differences in PRE perceptions about the effects of running footwear on injuries and biomechanics between RUN and HCPs

\begin{tabular}{|c|c|c|c|}
\hline & $\begin{array}{l}\text { RUN Mean } \\
(99 \% \text { Cl) } \\
(n=1564)\end{array}$ & $\begin{array}{l}\text { HCPs } \\
\text { Mean }(99 \% \mathrm{Cl}) \\
(\mathrm{n}=878)\end{array}$ & $P$ value \\
\hline $\begin{array}{l}\text { In your opinion, how important is footwear for the prevention of running } \\
\text { injuries?* }\end{array}$ & 7.6 (7.4 to 7.7$)$ & $6.2(6.0$ to 6.5$)$ & $<0.001 \S$ \\
\hline $\begin{array}{l}\text { Shoes with maximal cushioning help decrease ground impact and knee } \\
\text { joint forces. } \dagger\end{array}$ & $-0.2(-0.6$ to 0.3$)$ & $-4.6(-5.2$ to -4.1$)$ & $<0.001 \S$ \\
\hline $\begin{array}{l}\text { Shoes with minimal cushioning help decrease ground impact and knee } \\
\text { joint forces. } \dagger\end{array}$ & $0.2(-0.2$ to 0.6$)$ & 2.5 (1.9 to 3.0$)$ & $<0.001 \S$ \\
\hline A softer shoe sole helps to prevent injuries. $†$ & $-2.5(-2.8$ to -2.1$)$ & $-4.9(-5.4$ to -4.5$)$ & $<0.001 \S$ \\
\hline $\begin{array}{l}\text { A greater heel to toe drop (heel higher than the toes) helps to prevent } \\
\text { injuries. } \dagger\end{array}$ & $-3.2(-3.5$ to -2.8$)$ & $-5.3(-5.7$ to -4.8$)$ & $<0.001 \S$ \\
\hline $\begin{array}{l}\text { Changing to a different category of running shoes can lead to injury } \\
\text { (example: going from maximalist to minimalist). } \dagger\end{array}$ & $5.1(4.8$ to 5.4$)$ & 5.9 (5.5 to 6.3$)$ & $<0.001 \ddagger$ \\
\hline $\begin{array}{l}\text { Selecting shoes according to foot type (motion control shoes for low } \\
\text { arches, stability shoes for normal arches, neutral shoes for high arches) } \\
\text { helps to prevent injuries. } \dagger\end{array}$ & $1.6(1.2$ to 2.1$)$ & $-4.1(-4.7$ to -3.6$)$ & $<0.001 \ddagger$ \\
\hline
\end{tabular}

${ }^{*} 0=$ Not important at all, $10=$ Very important.

$\dagger-10=$ Strongly disagree, $10=$ Strongly agree.

$\ddagger$ Parametric tests.

$\S$ Non-parametric tests.

HCPs, healthcare professionals; RUN, runners.

Exploratory comparisons of perceived importance of footwear on injury risk between PRE and POST showed a statistically significant decrease after reading the module, both in RUN $(-1.2,99 \%$ CI -1.5 to 1.0 ; $\mathrm{p}<0.001)$ and HCPs $(-0.5,99 \%$ CI -0.8 to $0.2 ; \mathrm{p}<0.001)$. More exploratory analyses of changes in perceptions after the module are presented in online supplementary file 4 .

Table 4 Differences in perceptions at PRE between participants who completed only PRE and those who completed both PRE and POST

\begin{tabular}{|c|c|c|c|}
\hline & $\begin{array}{l}\text { PRE only } \\
\text { Mean }(99 \% \mathrm{Cl}) \\
(\mathrm{n}=1407)\end{array}$ & $\begin{array}{l}\text { PRE and POST } \\
\text { Mean }(99 \% \mathrm{Cl}) \\
(\mathrm{n}=1035)\end{array}$ & $P$ value \\
\hline $\begin{array}{l}\text { In your opinion, how important is footwear for the prevention of running } \\
\text { injuries?* }\end{array}$ & $7.3(7.1$ to 7.5$)$ & $6.8(6.6$ to 7.0$)$ & $<0.001 \S$ \\
\hline $\begin{array}{l}\text { Shoes with maximal cushioning help decrease ground impact and knee } \\
\text { joint forces. } \dagger\end{array}$ & $-1.0(-1.5$ to -0.5$)$ & $-2.8(-3.4$ to -2.3$)$ & $<0.001 \ddagger$ \\
\hline $\begin{array}{l}\text { Shoes with minimal cushioning help decrease ground impact and knee } \\
\text { joint forces. } \dagger\end{array}$ & $0.5(0.1$ to 0.9$)$ & 1.7 (1.2 to 2.2$)$ & $<0.001 \ddagger$ \\
\hline A softer shoe sole helps to prevent injuries. $\dagger$ & $-2.9(-3.3$ to -2.5$)$ & $-3.9(-4.4$ to -3.5$)$ & $<0.001 \ddagger$ \\
\hline $\begin{array}{l}\text { A greater heel to toe drop (heel higher than the toes) helps to prevent } \\
\text { injuries. } \dagger\end{array}$ & $-3.4(-3.8$ to -3.0$)$ & $-4.6(-5.0$ to -4.2$)$ & $<0.001 \S$ \\
\hline $\begin{array}{l}\text { Changing to a different category of running shoes can lead to injury } \\
\text { (example: going from maximalist to minimalist). } \dagger\end{array}$ & $5.3(5.0$ to 5.7$)$ & $5.5(5.1$ to 5.9$)$ & $0.468 \ddagger$ \\
\hline $\begin{array}{l}\text { Selecting shoes according to foot type (motion control shoes for low } \\
\text { arches, stability shoes for normal arches, neutral shoes for high arches) } \\
\text { helps to prevent injuries. } \dagger\end{array}$ & $0.3(-0.1$ to 0.8$)$ & $-1.5(-2.0$ to -1.0$)$ & $<0.001 \ddagger$ \\
\hline
\end{tabular}

${ }^{*} 0=$ Not important at all, $10=$ Very important.

$\dagger-10=$ Strongly disagree, $10=$ Strongly agree.

$\ddagger$ Parametric tests.

$\S N o n-$ parametric tests.

HCPs, healthcare professionals; RUN, runners. 


\section{DISCUSSION}

Running injury rates are high, ${ }^{26}$ and assessing knowledge about the effects of footwear on injury risk is potentially useful in addressing the issue. In a recent paper by Fokkema et al, nearly half of runners identified 'not knowing what to do' as a significant barrier to injury-prevention behaviours. ${ }^{27}$ This outlines the need for accessible and evidence-based educational resources like the online module designed in this study. Our primary findings were that perceptions about running shoes and injury risk differ between runners and HCPs, and that an online module is deemed useful to communicate the latest scientific evidence. This information can now be used to improve knowledge translation strategies to runners, and evaluate if improved knowledge changes behaviour, and ultimately reduces injury risk.

Footwear was generally perceived as an important part of running injury prevention by both runners and HCPs. This is in accordance with another study, in which runners ranked footwear as the second most important factor in preventing injury, just behind 'progression of the training programme'. ${ }^{27}$ Our data show that comfort was heavily accounted for when selecting a new pair of shoes. Since runners in our sample ranked injury prevention' as the third criterion for selecting running shoes, it is possible that they also associate comfort with injury prevention.

Runners commonly search for information on injury prevention. ${ }^{27}$ Our sample reported seeking advice from footwear retailers and websites more commonly than from HCPs. This outlines the importance of designing trustworthy sources of information for the public, but also to educate HCPs to ensure they are seen as knowledgeable on the topic. This is important as HCPs play a key role in the clinical management of injuries, and runners must therefore feel comfortable discussing multiple strategies-including footwear-during treatment planning.

Despite individual variations, our data do not support results from a previous study which reported that runners commonly perceive wearing the wrong shoe for foot type as a risk factor for running injuries. ${ }^{28}$ Differences between studies could be due to our recruitment occurring mainly through social media. It is possible that our sample was more aware of the scientific evidence than the general population of runners. Similarly, the level of knowledge in our sample of HCPs (87\% runners) may not be representative of all HCPs. Beliefs can be influenced by personal experience and interests. For example, our group previously found that recommendations about running and knee joint health were more restrictive when coming from non-running HCP than from running $\mathrm{HCP}^{29}$

Our evidence-based educational module was deemed helpful by a majority of respondents. However, the fact that perceptions at PRE differed between participants who went on to read the module and answer the POST questions compared with those who did not outlines the need to identify and target individuals who may benefit from an educational module. It is possible that those who declined to read the module and answer to POST did not feel the need to learn, did not want to challenge their beliefs or simply did not have time. Importantly, it remains uncertain if changes in knowledge would translate into changes in behaviour ${ }^{30}$ and eventually, reduced injury risk. A recent randomised clinical trial did not report changes in injuries in runners receiving an online multifactorial prevention programme compared with a group who did not. ${ }^{31}$ Unfortunately, no follow-up on compliance to the educational programme or perception on usefulness was provided in that study, which limits the interpretation of their results and comparisons with the current study. Despite obtaining a relatively high rating for overall usefulness, the efficacy of our module in reducing injuries remains purely hypothetical and should be tested in a future trial.

The design and inclusion of the educational module represent a strength of the current study. Our rigorous process that involved feedback from HCPs, as well as runners without research knowledge, was essential in optimising internal and external validity. ${ }^{32}$ However, this study also has limitations. First, given that research on running footwear is constantly evolving, the module will need periodic updating when tested in future trials. Second, using online data collection may be subject to response bias. It is impossible to ascertain if respondents provided honest answers, including if they were indeed runners or HCPs. This is an intrinsic limitation of such a study design. Third, our sample may not be representative of the whole population of runners and HCPs. Many factors including sources and strategies for recruitment, language and level of education can have a significant influence on responses and the effects of an educational module. In addition, footwear perceptions and preferences have even been suggested to be country specific. ${ }^{33}$ Despite improving generalisability by providing the questionnaire in two languages, research is needed to help assess beliefs in multiple countries and languages to eventually adapt educational resources to different cultures. Fourth, differences in the perceptions of those who filled out PRE compared with those who completed both PRE and POST, and the fact that less than half of participants decided to fill out the POST questions, represent potential sources of bias and outline the need to correctly identify individuals who could benefit from an educational module. Fifth, the absence of a control group receiving no education precludes us from concluding that changes noted by exploratory analyses were indeed due to the module, since simply participating in an online survey study about footwear could have influenced responses. Finally, it is uncertain if the effects of the educational module would last through time, given that we only explored immediate changes in perceptions. Since respondents' anonymity was prioritised, we were unable to follow-up at a later time. 


\section{CONCLUSION}

Results from this study suggest that runners commonly seek advice from footwear retailers, and rely mainly on comfort when selecting new footwear. Overall, runners generally perceived running shoes as more important in preventing injuries than did HCPs. Perceptions regarding the effects of specific footwear types, characteristics and selection strategy on biomechanics and injury risk were also different between HCPs and runners. An online evidence-based educational module was deemed useful by both subgroups. Further studies are needed to evaluate if such an educational module would affect behaviour and injury risk.

\section{Twitter Michael A Hunt @mhunt_ubc and Jean-Francois Esculier @JFEsculier}

Acknowledgements We would like to thank all runners, footwear retailers and healthcare professionals who gave their feedback on the survey and educational module and all those who participated in this study.

Contributors All authors contributed to the design of the study. GD, MH and JFE collected and analysed the data, and wrote the manuscript draft. All authors provided feedback and approved the final version.

Funding Salary support was provided by the Canadian Institutes for Health Research (JFE and MH), and the Michael Smith Foundation for Health Research (MH).

Competing interests JFE receives salary from The Running Clinic for teaching postgraduate continuing education to healthcare practitioners and providing lectures about running injury prevention to the public.

Patient consent for publication Not required.

Ethics approval This study was approved by the institutional research ethics committee: UBC Behavioural Research Ethics Board (H19-00239).

Provenance and peer review Not commissioned; externally peer reviewed.

Data availability statement Data are available in a public, open access repository, and are searchable from the homepage of the following website: circle. ubc.ca

Open access This is an open access article distributed in accordance with the Creative Commons Attribution Non Commercial (CC BY-NC 4.0) license, which permits others to distribute, remix, adapt, build upon this work non-commercially, and license their derivative works on different terms, provided the original work is properly cited, appropriate credit is given, any changes made indicated, and the use is non-commercial. See: http://creativecommons.org/licenses/by-nc/4.0/.

\section{ORCID iDs}

Michael A Hunt http://orcid.org/0000-0002-8648-1591

Jean-Francois Esculier http://orcid.org/0000-0003-0372-4525

\section{REFERENCES}

1 Hespanhol Junior LC, Pillay JD, van Mechelen W, et al. Metaanalyses of the effects of habitual running on indices of health in physically inactive adults. Sports Med 2015;45:1455-68.

2 van der Worp H, Vrielink JW, Bredeweg SW. Do runners who suffer injuries have higher vertical ground reaction forces than those who remain injury-free? A systematic review and meta-analysis. $\mathrm{Br} \mathrm{J}$ Sports Med 2016;50:450-7.

3 Chan ZYS, Zhang JH, Au IPH, et al. Gait retraining for the reduction of injury occurrence in novice distance runners: 1-year follow-up of a randomized controlled trial. Am J Sports Med 2018;46:388-95.

4 Dye SF. The pathophysiology of patellofemoral pain: a tissue homeostasis perspective. Clin Orthop Relat Res 2005;436:100-10.

5 Barton CJ, Bonanno DR, Carr J, et al. Running retraining to treat lower limb injuries: a mixed-methods study of current evidence synthesised with expert opinion. Br J Sports Med 2016;50:513-26.

6 Zadpoor AA, Nikooyan AA. The relationship between lower-extremity stress fractures and the ground reaction force: a systematic review. Clin Biomech 2011;26:23-8.

7 Richards CE, Magin PJ, Callister R. Is your prescription of distance running shoes evidence-based? Br J Sports Med 2009;43:159-62.
8 Napier C, Willy RW. Logical fallacies in the running shoe debate: let the evidence quide prescription. Br J Sports Med 2018;52:1552-3.

9 Theisen D, Malisoux L, Genin J, et al. Influence of midsole hardness of standard cushioned shoes on running-related injury risk. Br J Sports Med 2014;48:371-6.

10 Malisoux L, Chambon N, Urhausen A, et al. Influence of the heelto-toe drop of standard cushioned running shoes on injury risk in leisure-time runners: a randomized controlled trial with 6-month follow-up. Am J Sports Med 2016;44:2933-40.

11 Knapik JJ, Trone DW, Tchandja J, et al. Injury-reduction effectiveness of prescribing running shoes on the basis of foot arch height: summary of military investigations. J Orthop Sports Phys Ther 2014;44:805-12.

12 Malisoux L, Chambon N, Delattre N, et al. Injury risk in runners using standard or motion control shoes: a randomised controlled trial with participant and assessor blinding. Br J Sports Med 2016;50:481-7.

13 Ryan MB, Valiant GA, McDonald K, et al. The effect of three different levels of footwear stability on pain outcomes in women runners: a randomised control trial. $\mathrm{Br} J$ Sports Med 2011:45:715-21.

14 Perkins KP, Hanney WJ, Rothschild CE. The risks and benefits of running barefoot or in minimalist shoes: a systematic review. Sports Health 2014;6:475-80.

15 Chan ZYS, Au IPH, Lau FOY, et al. Does maximalist footwear lower impact loading during level ground and downhill running? Eur $J$ Sport Sci 2018;18:1083-9.

16 Kulmala J-P, Kosonen J, Nurminen J, et al. Running in highly cushioned shoes increases leg stiffness and amplifies impact loading. Sci Rep 2018;8:17496.

17 Pollard CD, Ter Har JA, Hannigan JJ, et al. Influence of maximal running shoes on biomechanics before and after a $5 \mathrm{k}$ run. Orthop Sports Med 2018;6:232596711877572.

18 Sinclair J, Richards J, Selfe J, et al. The influence of minimalist and maximalist footwear on patellofemoral kinetics during running. $J$ Appl Biomech 2016;32:359-64.

19 Rice HM, Jamison ST, Davis IS. Footwear matters: influence of footwear and foot strike on load rates during running. Med Sci Sports Exerc 2016;48:2462-8.

20 Esculier J-F, Dubois B, Bouyer LJ, et al. Footwear characteristics are related to running mechanics in runners with patellofemoral pain. Gait Posture 2017:54:144-7.

21 Bonacci J, Hall M, Fox A, et al. The influence of cadence and shoes on patellofemoral joint kinetics in runners with patellofemoral pain. $J$ Sci Med Sport 2018;21:574-8.

22 Sinclair J. Effects of barefoot and barefoot inspired footwear on knee and ankle loading during running. Clin Biomech 2014;29:395-9.

23 Tay CS, Sterzing T, Lim CY, et al. Overall preference of running shoes can be predicted by suitable perception factors using a multiple regression model. Hum Factors 2017:59:432-41.

24 Esculier J-F, Dubois B, Dionne CE, et al. A consensus definition and rating scale for minimalist shoes. J Foot Ankle Res 2015;8:42.

25 Warne JP, Gruber AH. Transitioning to minimal footwear: a systematic review of methods and future clinical recommendations. Sports Med Open 2017;3:33.

26 van Gent RN, Siem D, van Middelkoop M, et al. Incidence and determinants of lower extremity running injuries in long distance runners: a systematic review. Br J Sports Med 2007:41:469-80.

27 Fokkema T, de Vos R-J, Bierma-Zeinstra SMA, et al. Opinions, barriers, and facilitators of injury prevention in recreational runners. $J$ Orthop Sports Phys Ther 2019;49:736-42.

28 Saragiotto BT, Yamato TP, Lopes AD. What do recreational runners think about risk factors for running injuries? A descriptive study of their beliefs and opinions. J Orthop Sports Phys Ther 2014;44:733-8.

29 Esculier J-F, Krowchuk NM, Li LC, et al. What are the perceptions about running and knee joint health among the public and healthcare practitioners in Canada? PLoS One 2018;13:e0204872.

30 Hollman H, Ezzat A, Esculier J-F, et al. Effects of tailored advice on injury prevention knowledge and behaviours in runners: secondary analysis from a randomised controlled trial. Phys Ther Sport 2019;37:164-70.

31 Fokkema T, de Vos R-J, van Ochten JM, et al. Online multifactorial prevention programme has no effect on the number of runningrelated injuries: a randomised controlled trial. $\mathrm{Br} J$ Sports Med 2019;53:1479-85.

32 Belton J, Hoens A, Scott A, et al. Patients as partners in research: it's the right thing to do. J Orthop Sports Phys Ther 2019;49:623-6.

33 Kong PW, Lim CY, Ding R, et al. Subjective evaluation of running footwear depends on country and assessment method: a bi-national study. Ergonomics 2015;58:1589-604. 